\title{
An anthropometric study to evaluate the correlation between the occlusal vertical dimension and length of the thumb
}

This article was published in the following Dove Press journal:

Clinical, Cosmetic and Investigational Dentistry

3 February 2015

Number of times this article has been viewed

\author{
Bishal Babu Basnet \\ Prakash Kumar Parajuli \\ Raj Kumar Singh \\ Pramita Suwal \\ Pragya Shrestha \\ Dharanidhar Baral \\ Department of Prosthodontics, \\ BP Koirala Institute of Health \\ Sciences, Dharan, Nepal
}

Correspondence: Bishal Babu Basnet Department of Prosthodontics, BP Koirala Institute of Health Sciences, Dharan, Nepal Email bishal_bpkihs@yahoo.com; bishal_bishal@hotmail.com
Background: Establishment of proper occlusal vertical dimension (OVD) is one of the important tasks for successful prosthodontic therapy. An ideal method for determining OVD in terms of cost, time, and instrument requirements has been sought in prosthodontics by various investigators. However, no such single method has been formulated. In the current anthropometric study, the relationship of the length of the thumb to the OVD was tested in two ethnic groups of Nepal, Aryans, and Mongoloids. The result of this study can be useful in determining proper OVD in edentulous patients.

Aims and objectives: The primary aim of the present study was to evaluate the correlation between the length of the thumb and OVD in Aryan and Mongoloid ethnic groups. The secondary aim was to compare the correlation between OVD and other anatomic measurements (eye-ear distance and pupil-to-rima oris distance) in these ethnicities.

Materials and methods: The OVD, thumb length, eye-ear distance and distance between pupil of eye and rima oris were measured in a total of 500 adult dentulous volunteers. The correlation between OVD and thumb length as well as other anatomic measurements was checked with Pearson's product moment correlation coefficient. Linear regression analysis was performed to determine the relationship of OVD to the length of the thumb.

Results: The thumb length was significantly $(P \leq 0.05)$ correlated with strong and positive values (Pearson's coefficient $=0.874$ in the whole population, 0.826 in Aryans, and 0.944 in Mongoloids). Regression analysis showed that thumb length was significantly related to OVD in both ethnic groups.

Conclusion: Within the limitations of the present study, the result implies that thumb length can be used as an adjunct for establishing OVD in the edentulous patients.

Keywords: thumb, prosthodontic, caliper, rima oris, pupil of eye, edentulous patients

\section{Introduction}

The different components of the masticatory system are closely related. They are composed of the jaws and teeth, the temporomandibular system, and the muscles of mastication. In being edentulous, the teeth and their associated periodontal ligament nerves are lost, and replacing the function of lost teeth is the aim of prosthodontic treatment. Establishing the correct vertical dimension of the edentulous mouth is one major concern in treating edentulous patients. In addition to functional importance, the lower third of the face affects one's facial expressions and appearance. The restoration of a pleasing appearance is one of the primary goals of aesthetic dentures. The vertical dimension that is appropriate, stable occlusal contacts that are harmonious with the existing temporomandibular joints and masticatory muscles, and consistent contours 
with the surrounding facial musculature will help to adapt the complete dentures to the rest of the masticatory system. ${ }^{1}$ Vertical dimension is expressed in terms of occlusal vertical dimension (OVD) and vertical dimension at rest (VDR). In clinical practice, a fully precise method of determining the exact vertical relation of occlusion does not exist. ${ }^{2}$ The correct measurement of the natural OVD is the most essential criterion while fabricating successful complete dentures. Glossary of Prosthodontic Terms defines the OVD as the distance between two selected points when the occluding members are in contact, ${ }^{3}$ and the rest vertical dimension as the distance between two selected points when the mandible is in the physiologic rest position. ${ }^{4}$ Pre-extraction records have been useful in determining the original vertical dimension. ${ }^{5}$ The vertical dimension can be appropriate if it is measured when natural teeth are present. Silverman ${ }^{6}$ has advised recording the closest speaking space of all patients after they are 20 years of age for use later in their lives. Anatomic landmarks of the face can also be correlated with measurement of the vertical dimension in edentulous patients in case there are no pre-extraction records. Although there are instruments like the Dakometer or the Willis gauge, it is argued that a more reliable method is to measure the distance between the upper and the lower labial frena with dividers when the teeth are in centric occlusion. ${ }^{7}$ Turner ${ }^{8}$ developed a "cut-out method" using a simple pantograph. Swenson ${ }^{9}$ described the construction of a clear resin mask of the lower part of the face. Tallgren ${ }^{10}$ concluded that the vertical dimension of rest position adapts to changes in the vertical dimension of occlusion in both dentulous and edentulous patients. Tueller ${ }^{11}$ used an electronic method to determine the vertical separation of the jaws. Goodfriend ${ }^{12}$ suggested that the distance between the pupil of the eye and the rima oris equaled the distance from the subnasion to the gnathion, which was popularized by Willis. ${ }^{13} \mathrm{McGee}^{14}$ correlated three measurements with the vertical dimension of occlusion, viz, the distance from the center of the pupil of the eye to a line projected laterally from the median line of the lips; the distance from the glabella to the subnasion; and the distance between the angles of the mouth with the lips in repose. Studies pertaining to the OVD have been tabulated in Table 1 .

OVD is argued to be the distance between the tip of the thumb and the tip of the index finger when the hand lies flat, fingers next to each other. ${ }^{15}$ The hand and the wrist have been used to assess the growth of dentofacial structures as skeletal maturity indicator and ossification of the ulnar metacarpophalangeal sesamoid of the thumb occurs by 11 years in female and 12.3 years in male. ${ }^{16,17}$ The thumb is
Table I Methods to determine occlusal vertical dimension

\begin{tabular}{|c|c|}
\hline Authors & Method utilized \\
\hline Goodfriend ${ }^{\prime 2}$ & $\begin{array}{l}\text { Distance between pupil of eye and rima oris equaled the } \\
\text { distance from subnasion to gnathion }\end{array}$ \\
\hline $\mathrm{McGee}^{14}$ & $\begin{array}{l}\text { I. Distance from the center of the pupil of the eye to a } \\
\text { line projected laterally from the median line of the lips } \\
\text { 2. Distance from the glabella to the subnasion } \\
\text { 3. Distance between the angles of the mouth with the } \\
\text { lips in repose }\end{array}$ \\
\hline Silverman ${ }^{6}$ & $\begin{array}{l}\text { Record closest speaking space of all patients after they } \\
\text { are } 20 \text { years of age for use later in their lives }\end{array}$ \\
\hline Swenson 9 & Construct a clear resin mask of the lower part of the face \\
\hline Turner $^{8}$ & "Cut-out method" using a simple pantograph \\
\hline Tueller ${ }^{\prime \prime}$ & Electronic method \\
\hline
\end{tabular}

considered one of the few human characteristics, important among all digits, and it is long and well developed through evolution. ${ }^{18}$ Studies regarding the thumb are found pertaining to industrial purposes. The anthropometric measurements of the hand, thumb, and other digits are utilized in constructing gloves, design and sizing of hand tools, controls, knobs, and other applications in various kinds of precision and powergrips. From the evolutionary point of view, the thumb is shorter than the other digits; the requirement of a firm grip and the tolerance of large stresses associated with use and manufacture of stone tools gave it distinctive features. ${ }^{19}$

Correlation studies between the length of the thumb to the length of the lower facial height can help the clinician establish the correct OVD in the treatment of patients requiring restorations like the complete denture. The aim of the study was to determine the correlation between the OVD and the length of the thumb and also to compare the correlation in two predominant ethnic groups of Nepal, namely, the Aryans and the Mongoloids.

\section{Materials and methods}

The study was conducted among 500 adult volunteers (250 Aryans and 250 Mongoloids) that included doctors, staff, and students of the College of Dental Surgery and students of local colleges in Dharan municipality after obtaining written consent from them. The ethical approval for this study was obtained from the Institutional Ethical Review Board (Ref No 408/070/071). Subjects with complete natural dentition (third molar not taken into account), intact upper and lower teeth without any artificial partial or full crowns, and with straight profile on visual examination were included in the study. Any history of prosthodontic/orthodontic/surgical treatment, presence of large carious lesions, abnormality or absence of thumb/s, 
or any hormonal abnormalities (eg, gigantism, acromegaly) were the exclusion criteria.

Each subject was asked to place his or her hand on a graph paper with the palm facing downward, keeping the fingers separated and the thumb lying comfortably. A sliding caliper was used to measure the length of the thumb (Figure 1), as in the method used by Kumar et al. ${ }^{20}$ The proximal point on the radial side of the proximal crease over the first metacarpophalangeal joint and the distal point in the dactylion, the distal most part of the thumb, were marked. The ends of the caliper were placed over these two landmarks, and the distance between them gave the maximum length of thumb. The lengths of both thumbs were measured on the dorsal and ventral aspects and on the graph paper. Their average values were recorded.

To measure the OVD, commonly used methods in the Department of Prosthodontics, BP Koirala Institute of Health Sciences (BPKIHS) were employed (Figures 2 and 3). The subject was seated comfortably in the dental chair in a fully upright position, with the back of the subject in maximal contact with the back of the chair. A headrest was used to support the head with the ala-tragus line of the subject in a horizontal position, which was maintained throughout the measurements. He or she was made to occlude the teeth in maximum intercuspation. Then two markings were placed on the tip of the nose and the most prominent point on the chin. The distance between them was measured with a Boley gauge (Taurus 811-2, SS Medident Instruments, Sialkot, Pakistan).

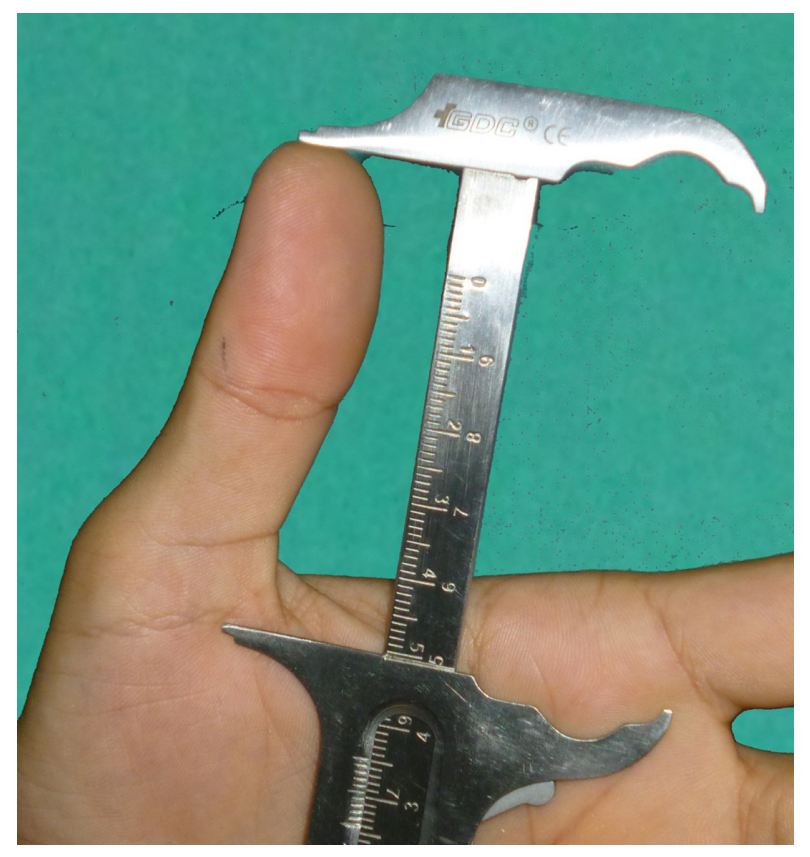

Figure I Measurement of thumb length.

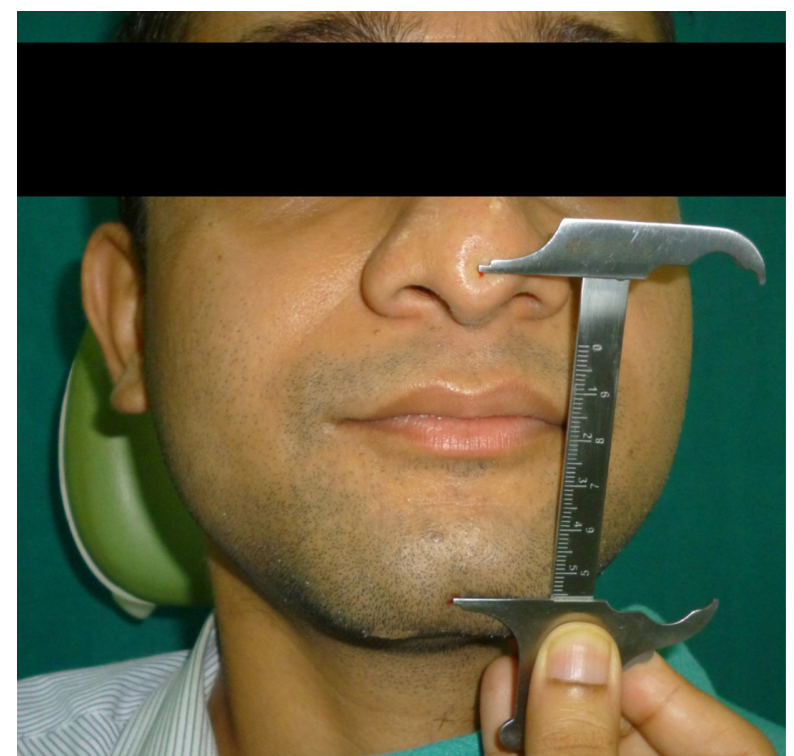

Figure 2 Measurement of OVD by Boley gauge.

Using a modified sliding caliper with its one end resting on the base of the nose while the other, longer, end projected at the base of the chin, an arbitrary measurement was taken. The measurement was verified and recorded. All methods were used to take at least three measurements, and the average of all was noted.

For correlating other anatomic distances with the OVD, two other distances between the anatomical landmarks for the measurement of the OVD were also recorded. These were the distance from the rima oris to the pupil of the eye and the distance from the lateral border of the outer canthus to the tragus of the ear (Figures 4 and 5).

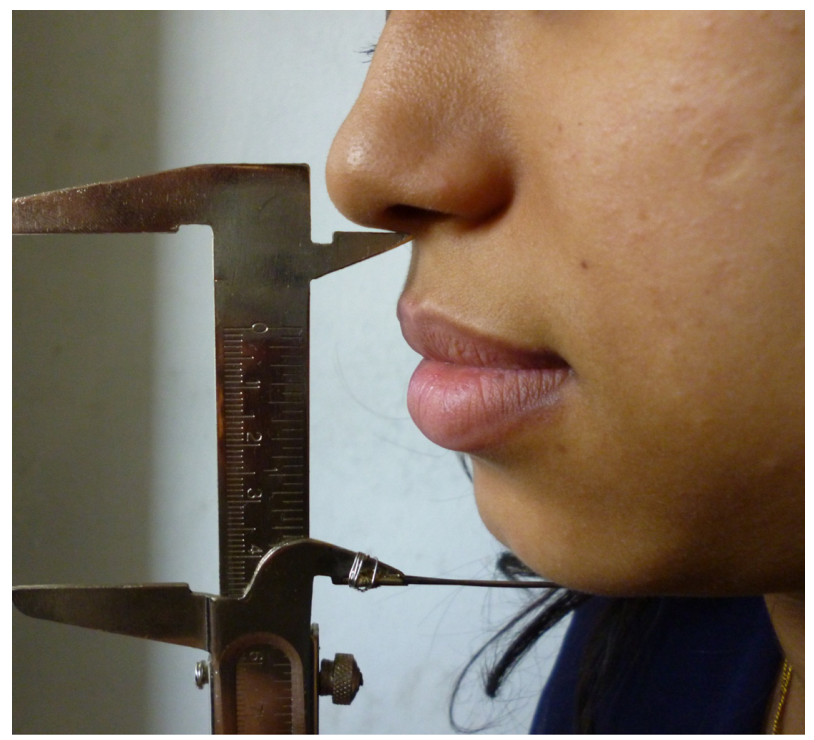

Figure 3 Measurement of OVD with modified vernier calipers. 


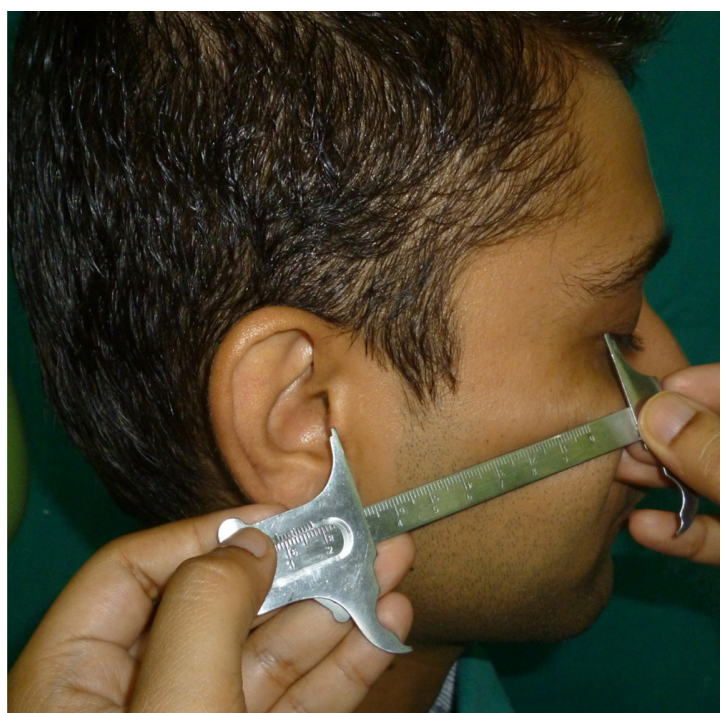

Figure 4 Measurement of eye-ear distance.

\section{Results}

In this study, an equal number (250) of volunteers of Aryan and Mongoloid ethnicities were taken. Among them, 286 (57\%) were males and 214 (43\%) were females. More female volunteers were observed in the Mongoloid

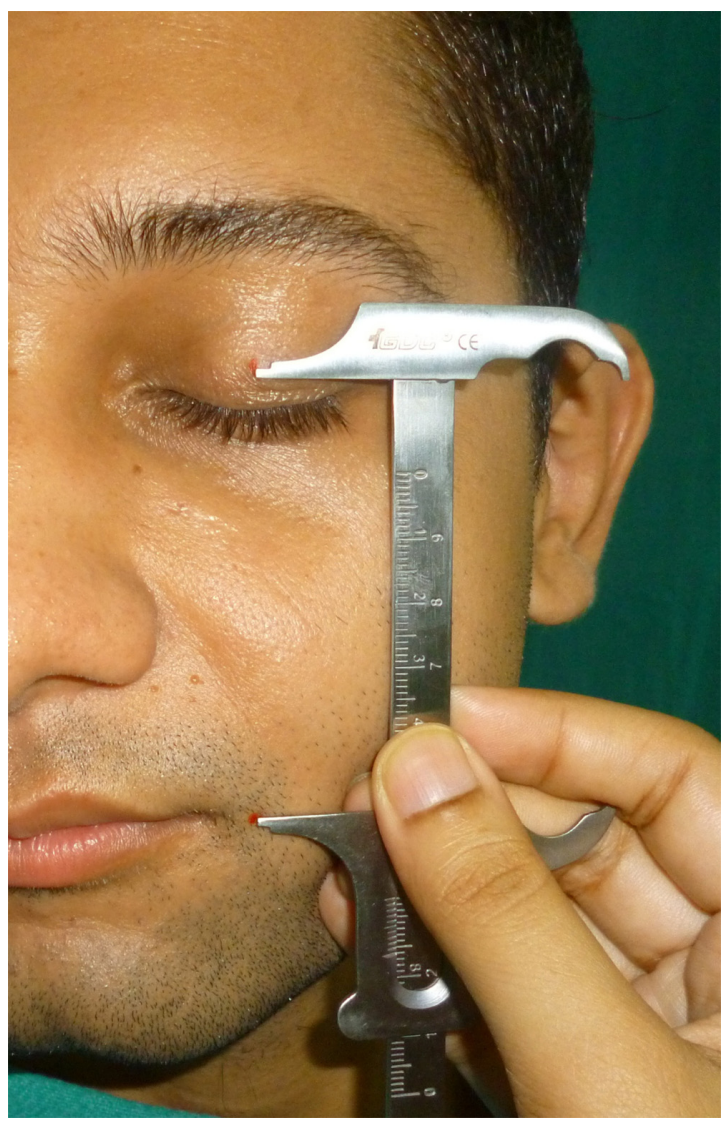

Figure $\mathbf{5}$ Measurement of distance between rima oris and pupil of eye. group (29\%), whereas more males were observed in the Aryan group (36\%).

The mean age was $24.91 \pm 5.85$ years and ranged from 19 to 56 years. The maximum number of subjects were from the age groups 21-30 (71.8\%), which comprised 183 Mongoloids and 176 Aryans. The age group distribution is shown in Table 2. The mean OVD of the population was $66.26 \pm 5.04 \mathrm{~mm}$, and the mean thumb length (TL) of the studied population was $59.32 \pm 4.58 \mathrm{~mm}$. The mean distance from the pupil of the eye to the rima oris was found to be $65.52 \pm 5.28 \mathrm{~mm}$. Likewise, the mean eye-ear distance (E-E) was $70.60 \pm 4.51 \mathrm{~mm}$. The box plot shows the mean and range of various measurements (Figure 6).

The mean OVD of the Aryan group was $67.93 \mathrm{~mm}$, which was found to be shorter in the Mongoloid population (64.60 $\mathrm{mm}$ ). Similarly, the TL and E-E were longer in the Aryan group than in the Mongoloid group (Table 3). However, the rima oris-to-pupil distance ( $\mathrm{RO}-\mathrm{Pu})$ of the Aryan group $(64.29 \mathrm{~mm})$ was found shorter than that of the Mongoloid group (66.74 mm).

The independent samples $t$ test was used to compare the means of the OVD, TL, RO-Pu, and E-E of males and females in both ethnicities. The results showed that there was a statistically significant difference between the measurements of male and female for all the parameters $(P<0.001)$ in the Mongoloid population, with males having a longer dimension of OVD, TL, RO-Pu, and E-E. There was a statistically significant difference between the means of the parameters in the Aryan population as well, with males having longer dimensions of the studied parameters.

The TL was significantly correlated in the whole sample (Table 4). Also, the TL was positively and strongly correlated ( $r=0.838$ in males and $r=0.864$ in females), whereas the correlation of the RO-Pu was found to be mild ( $r=0.291$ for males and 0.278 for females) but statistically significant in both genders. The correlation between the eye-to-ear distance and the OVD was found to be significant only in males. In females, the correlation was statistically not significant $(P=0.836)$.

While studying the population in two variables, gender and ethnicity, the TL was found significantly correlated in both ethnicities. The correlation was strong and positive

Table 2 Distribution of age groups by ethnicity of volunteers

\begin{tabular}{llll}
\hline Age group & Mongoloid (\%) & Aryan (\%) & Total (\%) \\
\hline$\leq 20$ & $3 \mathrm{I}(\mathrm{I} 2.4)$ & $52(20.8)$ & $83(16.6)$ \\
$2 \mathrm{I}-30$ & $183(73.2)$ & $176(70.4)$ & $359(7 \mathrm{I} .8)$ \\
$3 \mathrm{I}-40$ & $28(1 \mathrm{I} .2)$ & $1 \mathrm{I}(4.4)$ & $39(7.8)$ \\
$\geq 4 \mathrm{I}$ & $8(3.2)$ & $1 \mathrm{I}(4.4)$ & $19(3.8)$ \\
Total & $250(100)$ & $250(100)$ & $500(100)$ \\
\hline
\end{tabular}




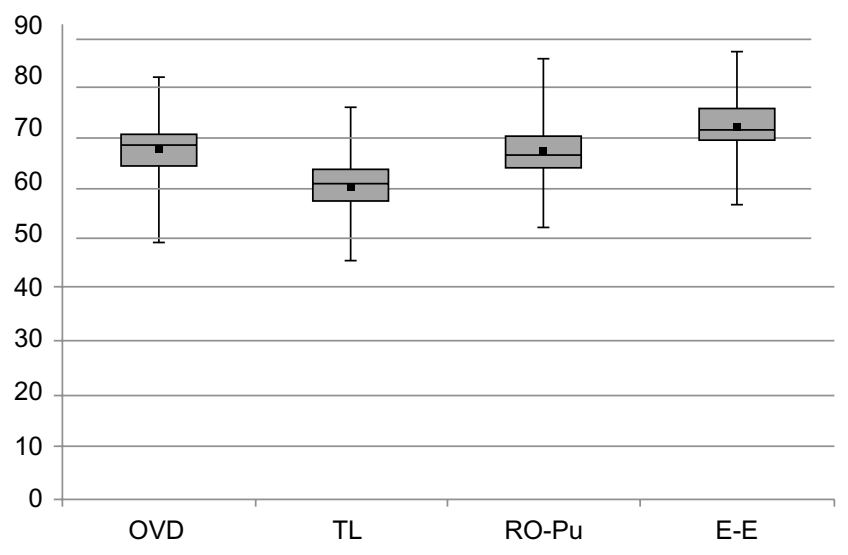

Figure 6 Box plot showing mean, maximum, minimum, and quartile values of OVD, TL, RO-Pu, and E-E.

Abbreviations: OVD, occlusal vertical dimension; TL, thumb length; RO-Pu, rima oris-to-pupil distance; E-E, eye-ear distance.

in both Mongoloids ( $r=0.944)$ and Aryans $(r=0.826)$. The correlation coefficients between the OVD and the other parameters were also statistically significant in both Aryans and Mongoloids, but they were mild to moderate. As both ethnic groups were further divided by gender, the TL was significantly correlated in the Mongoloid population in both genders. In the Aryan population, the correlation was relatively weaker than in the Mongoloid population.

Univariable linear regression analysis was performed for the prediction of the OVD using TL in both ethnic groups. From Table 5, the following equations were determined for the whole population under study $(\mathrm{N}=500)$, the Aryan population and the Mongoloid population.

1. Whole population, $\mathrm{OVD}=9.197+0.962 \times \mathrm{TL}$

2. Aryan population, $\mathrm{OVD}=14.801+0.844 \times \mathrm{TL}$

3. Mongoloid population, $\mathrm{OVD}=7.392+0.977 \times \mathrm{TL}$.

\section{Discussion}

The correlation between the OVD and the TL was found strong and positive $(r=0.874)$ in the whole population of the study, as shown by Table 4 . The correlation was statistically

Table 3 Comparison of mean between ethnicity and different parameters

\begin{tabular}{lllll}
\hline Parameters & Mean \pm SD & & P-value & Remarks \\
\cline { 2 - 3 } & Mongoloid & Aryan & & \\
\hline OVD & $64.60 \pm 4.48$ & $67.93 \pm 5.02$ & $<0.001$ & Sig \\
TL & $58.54 \pm 4.33$ & $60.09 \pm 4.69$ & $<0.00$ I & Sig \\
RO-Pu & $66.74 \pm 4.71$ & $64.29 \pm 5.54$ & $<0.00$ I & Sig \\
E-E & $70.18 \pm 4.05$ & $71.18 \pm 4.87$ & 0.014 & Sig \\
\hline
\end{tabular}

Note: $P$-value significant at $\leq 0.05$ level.

Abbreviations: SD, standard deviation; Sig, significant OVD, occlusal vertical dimension; $\mathrm{TL}$, thumb length; RO-Pu, rima oris-to-pupil distance; E-E, eye-ear distance.
Table 4 Correlation matrix between OVD and other parameters ( $\mathrm{TL}, \mathrm{RO}-\mathrm{Pu}$, and $\mathrm{E}-\mathrm{E})$ in total sample $(\mathrm{N}=500)$

\begin{tabular}{|c|c|c|c|c|c|c|c|}
\hline \multirow[t]{2}{*}{ Variables } & \multicolumn{2}{|c|}{ OVD } & \multicolumn{2}{|l|}{ TL } & \multicolumn{2}{|c|}{ RO-Pu } & \multirow[t]{2}{*}{ E-E } \\
\hline & $r$ & $P$-value & $r$ & $P$-value & $r$ & $P$-value & \\
\hline OVD & I & & & & & & \\
\hline $\mathrm{TL}$ & 0.874 & $<0.001$ & I & & & & \\
\hline RO-Pu & 0.318 & $<0.001$ & 0.327 & $<0.001$ & I & & \\
\hline$E-E$ & 0.262 & $<0.001$ & 0.268 & $<0.001$ & 0.283 & $<0.001$ & I \\
\hline
\end{tabular}

Note: $P$-value significant at $\leq 0.05$ level.

Abbreviations: OVD, occlusal vertical dimension; TL, thumb length; RO-Pu, rima oris-to-pupil distance; E-E, eye-ear distance.

significant. RO-Pu and E-E were also significantly correlated with OVD; however, the correlation was mild.

The ideal method of restoring OVD and thus promoting better oral health has been quite an interesting and important aspect of prosthodontics, yet the correct and universal method has not been found. There are several thoughts and evidences regarding restoration of the correct OVD. These include the use of anterior teeth measurements, ${ }^{21}$ closest speaking space, ${ }^{6}$ swallowing method, ${ }^{22}$ patient's neuromuscular perception, ${ }^{23}$ cephalometric radiographs, ${ }^{24,25}$ intraoral and extraoral anatomic landmarks, ${ }^{26}$ and measurement of fingers. ${ }^{27}$ All of these methods inherently possess some kinds of disadvantages. Some have errors in measurement, while others are prone to difficult application, higher cost, or longer time for application. Any variation in determining OVD can be detrimental to the aesthetics of facial soft tissues, induce speech difficulties, and cause temporomandibular joint discomfort. Pre-extraction record is undoubtedly superior to these methods. ${ }^{5}$ But recording the OVD of all patients and keeping it for future use is not always possible. In the absence of pre-extraction records, knowledge of aesthetics, relationship of teeth to the ridges, measurements relative to the lip length, and use of phonetics and other methods are employed. This study was undertaken to investigate the relationship between the OVD and the length of the thumb, taking into account that the body parts grow proportionately. This provided data

Table 5 Linear regression analysis for study population with OVD as dependent variable and thumb length as independent variable

\begin{tabular}{lllllll}
\hline Population & $\boldsymbol{R}$ & $\boldsymbol{R}^{\mathbf{2}}$ & Adjusted $\boldsymbol{R}^{\mathbf{2}}$ & $\mathbf{S E}$ & $\mathbf{B}$ & $\boldsymbol{P}$-value \\
\hline Total & $0.874^{\mathrm{a}}$ & 0.764 & 0.763 & 2.452 & 9.197 & $<0.00 \mathrm{I}$ \\
$(\mathrm{N}=500)$ & & & & & 0.962 & \\
Aryan & $0.826^{\mathrm{a}}$ & 0.683 & 0.682 & 2.832 & $14.80 \mathrm{I}$ & $<0.00 \mathrm{I}$ \\
$(\mathrm{N}=250)$ & & & & & 0.884 & \\
Mongoloid & $0.944^{\mathrm{a}}$ & $0.89 \mathrm{I}$ & 0.890 & $\mathrm{I} .486$ & 7.392 & $<0.00 \mathrm{I}$ \\
$(\mathrm{N}=250)$ & & & & & 0.977 & \\
\hline
\end{tabular}

Notes: $P$-value significant at $\leq 0.05$ level. aPredictors: (constant) thumb length. Abbreviations: OVD, occlusal vertical dimension; SE, standard error. 
on a selected sample of dentulous Nepalese population of two different ethnicities that can become a reference for the establishment of the OVD in edentulous patients.

The study showed sexual variation, with higher values of OVD and TL in males than in females in both the ethnic groups. This agrees with the results of previous studies, ${ }^{27-30}$ and could be related to postpuberty levels of androgen exposure. $^{31}$

In the present study, the OVD was found to be $68.12 \pm 4.63 \mathrm{~mm}$ in males and $63.78 \pm 4.47 \mathrm{~mm}$ in females. These were found to be longer than the studied samples of the Indian population in a study by Ladda et $\mathrm{al}^{27}(61.4 \pm 4.2$ $\mathrm{mm}$ in males and $56.7 \pm 3.0 \mathrm{~mm}$ in females) and Kulkarni and Kohli $^{30}$ (54-59 $\mathrm{mm}$ in females and 62-65 $\mathrm{mm}$ in males). In agreement with the present study, the distance between ANS and Me from cephalometric radiograph in Serbian population was $67.87 \pm 5.67 \mathrm{~mm}$ in males and $61.51 \pm 5.06 \mathrm{~mm}$ in females. ${ }^{28}$ Similar measurements were observed in the Iraqi adult population reported by Al-Hamdany and Kasaab, ${ }^{29}$ where the OVD in 75 students was $66.74 \mathrm{~mm}$ (6.468); in males it was $68.25 \mathrm{~mm}(6.134)$ and in females $63.99 \mathrm{~mm}$ (6.254). These values are consistent with those of the current study. In contrast, many studies ${ }^{2,30,32,33}$ have lower values of OVD than our population. This may be partly due to the fact that the sample sizes in these studies were either very large or very small as compared with those in our present study. The difference can be attributed to the racial variation of body size, methods of measurements, and anatomic landmarks used for measurements.

Geerts et $\mathrm{al}^{33}$ assessed the accuracy of the chin-nose distance measurement. The compressibility of skin over these anatomic landmarks cannot be avoided, so there may be some degrees of errors in measurement. Measurement by modified calipers invariably led to some differences in the various studies. The present study did not compare these two procedures of measuring the OVD; rather, the mean of these two were taken into consideration.

In the present study, two ethnic groups were compared. The mean OVD in Mongoloids and Aryans was found to be $64.60 \pm 4.48$ and $67.93 \pm 5.02 \mathrm{~mm}$, respectively. The independent sample $t$ test showed it to be statistically significant $(P \leq 0.05)$. This may be considered to be due to different facial proportions in these ethnic groups.

The limitations of this study were errors while measuring dimensions in large sample, and only two ethnic groups (Aryan and Mongoloid) were considered in the present study, so the findings cannot be extrapolated to other ethnic groups or races. Further studies in large sample and other ethnic groups are recommended to endorse or refute the findings of the present study.

Subject to the aforementioned limitations, the following conclusions were drawn from this study:

1. Correlation of the length of the thumb to the OVD was statistically significant, with a Pearson's correlation coefficient $(r)$ of 0.826 in the Aryan and 0.944 in the Mongoloid population.

2. The correlation between the length of the thumb and OVD was positive and strong in the whole population as well as in both ethnicities, and a stronger correlation was found in Mongoloids than in Aryans in the studied sample.

3. There was a statistically significant but mild correlation between OVD and other measurements (distance between the RO-Pu and E-E).

\section{Acknowledgments}

The authors would like to acknowledge all the volunteers who participated in the study and also the staff of the department for their technical assistance.

\section{Disclosure}

The authors report no conflicts of interest in this work.

\section{References}

1. Zarb GA, Bolender CL. Prosthodontic Treatment for Edentulous Patient: Complete Dentures and Implant Supported Prostheses. 12th ed. St Louis, MO: Mosby; 2004:268.

2. Delic Z, Simunovic-Soskic M, Perinic-Grzic R, Vukovojac S, Rajic Z, Kuna T. Evaluation of craniometric methods for determination of vertical dimension of occlusion. Coll Antropol. 2000;1(Suppl 24):31-35.

3. The glossary of prosthodontics terms. J Prosthet Dent. 2005; 94(1):57.

4. The glossary of prosthodontics terms. J Prosthet Dent. 2005; 94(1):69.

5. Bissau M. Pre-extraction records for complete denture fabrication: a literature review. J Prosthet Dent. 2004;91(1):55-58.

6. Silverman MM. The speaking method in measuring vertical dimension. J Prosthet Dent. 1953;3(2):193-199.

7. Turrell AJW. The pre-extraction recording of the vertical dimension by an intraoral method. Dent Pratt Dent Rec.1955;6:68-72.

8. Turner LC. The profile tracer: method for obtaining accurate preextraction records. J Prosthet Dent. 1969;21:364-370.

9. Swenson MG. Complete Dentures. 4th ed. St Louis, MO: Mosby; 1959:125.

10. Tallgren A. Changes in adult face height due to ageing, wear and loss of teeth. Acta Odontol Stand. 1957;15(Suppl 24):1-112.

11. Tueller VM. The relationship between the vertical dimension of occlusion and forces generated by closing muscles of mastication. J Prosthet Dent. 1969;22:284-288.

12. Goodfriend DJ. Symptomatology and treatment of abnormalities of the mandibular articulation. Dent Cosmos. 1933;75:844, 947, 1106.

13. Willis FM. Features involved in full denture prostheses. Dent Cosmos. $1935 ; 77: 851-854$

14. McGee G. Use of facial measurements in determining vertical dimension. J Am Dent Assoc.1947;35:342-350. 
15. Misch CE. Contemporary Implant Dentistry. 2nd ed. St Louis, MO: Mosby; 1999:638.

16. Alkofide E, Al-Balbeesi H, Al-Kawari H, et al. Pre-clinical orthodontics and dentofacial orthopedics: practical manual [Internet]. 2010 [cited December 1, 2013]. Available from: http://faculty.ksu.edu.sa/masiry/ Documents. Accessed December 18, 2014.

17. Fishman LS. Radiographic evaluation of skeletal maturation: a clinically oriented method based on hand-wrist films. Angle Orthod. 1982;52(2):88-112.

18. Sunil TM. Clinical indicators of normal thumb length in adults. J Hand Surg Am. 2004;29A(3):489-493.

19. Marzke MW. Evolutionary development of human thumb. Hand Clin. 1992;8(1):1-8.

20. Kumar L, Jain SK, Mishra P. Study of correlation between length of thumb and stature in Uttarakhand population. J Indiana Acad Forensic Med. 2012;34(3):203-205.

21. Fayz F, Eslami A, Graser GN. Use of anterior teeth measurements in determining occlusal vertical dimension. J Prosthet Dent. 1987;58(3): 317-322.

22. Shanahan TEJ. Physiologic vertical dimension and centric relation. J Prosthet Dent. 1956;6:741-747.

23. Lytle RB. Vertical relation of occlusion by the patient's neuromuscular perception. J Prosthet Dent. 1964;14(1):12-21.

24. Basler FL, Douglas JR, Moulton RS. Cephalometric analysis of the vertical dimension of occlusion. J Prosthet Dent. 1961;11:831-835.
25. Hull CA, Junghans JA. A cephalometric approach to establishing the facial vertical dimension. J Prosthet Dent. 1968;20(1):37-42.

26. Fayz F, Eslami A. Determination of occlusal vertical dimension: a literature review. J Prosthet Dent. 1988;59(3):321-323.

27. Ladda R, Bhandari AJ, Kasat VO, Angadi GS. A new technique to determine vertical dimension of occlusion from anthropometric measurements of finger. Indian J Dent Res. 2013;24:316-320.

28. Strajnic L, Stanisic-Sinobad D, Markovic D, Stojanovic L. Cephalometric indicators of the vertical dimension of occlusion. Coll Antropol. 2008;32(2):535-541.

29. Al-Hamdany AK, Kassab NH. Correlation of vertical dimensions of soft tissue facial profiles. Al-Rafidain Dent J. 2010;10(2): $243-253$.

30. Kulkarni N, Kohli M. Estimation and correlation of individual facial height and total body height. J Int Oral Health. 2011;3(2):37-42.

31. Jackson C. Prediction of hemispheric asymmetry as measured by handedness from digit length and 2D:4D digit ratio. Laterality. 2008;13:34-50.

32. Millet C, Jeannin C, Vincent B, Malquarti G. Report on the determination of occlusal vertical dimension and centric relation using swallowing in edentulous patients. J Oral Rehabil. 2003;30:1118-1122.

33. Geerts GA, Stuhlinger ME, Nel DG. A comparison of the accuracy of two methods used by pre-doctoral students to measure vertical dimension. J Prosthet Dent. 2004;91(1):59-66.
Clinical, Cosmetic and Investigational Dentistry

\section{Publish your work in this journal}

Clinical, Cosmetic and Investigational Dentistry is an international, peer-reviewed, open access, online journal focusing on the latest clinical and experimental research in dentistry with specific emphasis on cosmetic interventions. Innovative developments in dental materials, techniques and devices that improve outcomes and patient satisfaction

\section{Dovepress}

and preference will be highlighted. The manuscript management system is completely online and includes a very quick and fair peerreview system, which is all easy to use. Visit http://www.dovepress. com/testimonials.php to read real quotes from published authors. 